\title{
A Web-based Housing and Mobility Cost Calculator for Salzburg
}

\author{
Sebastian CADUS \\ University of Salzburg / Austria·Sebastian_Michael.Cadus@stud.sbg.ac.at
}

This contribution was double-blind reviewed as full paper.

\begin{abstract}
In the past decades, the development of housing estate and mobility behaviour in the Alpine space has been characterised by growing land use and landscape fragmentation on the one hand, as well as increasing commuting distances and motorised individual traffic on the other hand. Both processes mutually influence each other, since the location of housing is a central determinant for everyday mobility requirements. However, despite several interdependencies, housing decisions are generally made without comprehensive knowledge about their far-reaching implications. The work at hand presents the working steps to develop a calculator for private households in the province of Salzburg. The Web-based tool is meant to both indicate the impact of housing and mobility decisions on a household's expenditure, and to illustrate the influence of housing locations on mobility opportunities. Therefore the transparency of induced cost structures shall be fostered, and the awareness of households on existing interdependencies shall be raised. In the end, this shall contribute to more long-sighted housing and mobility decisions, strengthening structurally integrated areas with less traffic and more environmentally sound modes of transport. As a result, the calculator was made available on-line and free of charge at www.moreco.at/haushaltsrechner. In conclusion, it can be found that in the long run the share of mobility costs in a household's budget gains importance. Cheap land prices tend to face high mobility costs and hence overall costs may become more expensive in peripheral regions, compared to well integrated locations. The tool shall contribute to illustrate this finding, breaking the fixation on pure land prices in housing decisions.
\end{abstract}

\section{Introduction}

For many decades, housing and transport developments in Europe have countervailed a sustainable development: Investments in road construction as well as building land designation increased steadily (WÜRDEMANN \& HELD 2009, 752). In addition, travel speed rose and the desired permeability of space allowed further distances at almost constant travel time. Hence the importance of distance decreased, and the locations of residences and businesses became more or less arbitrary. As a consequence, housing development was (and still is) characterised by persistent land use and landscape fragmentation (VCÖ 2007 11). The development of transport activities in turn may be described by growing motorisation, longer distances, and increasing use of motorised individual transport at the expense of travels on foot and public transport. Changing spatial offers (and deficits) 
created individual travel behaviour, allowing citizens to reach farther destinations quickly and at a low cost. At the same time, concentration processes of the retail industry and (public) services continued, leading to a constitution of car-dependent settlements and a decreased quality of mobility. It must therefore be recognised that both housing and transport development are closely related to each other, and substantially influenced by suburbanisation processes. Despite the fact that significant re-urbanisation trends have occurred over the last years (ADAM et al. 2008, 399f.), these cannot yet be interpreted as stable trends of settlement development (HoLZ-RAU et al. 2010, $11 \mathrm{f}$.). Neither in shrinking nor in growing regions a 'renaissance' of urban areas will happen by itself, and the development of strategies to mitigate urban-rural migration remains a current challenge 1 .

The choice of residential or business locations is a key decision in the life of people, and crucial for the success of companies. It directly influences both the individual mobility of people and mobility costs for many years (Figure 1 illustrates the result of a study on housing and mobility costs in the metropolitan region of Hamburg in 2003, indicating the influence of location on mobility costs). For this reason the decision, and especially the thereby implied consequences, should be considered carefully. Yet, it is very difficult to comprehensively assess the range of medium- and long-term effects of this choice. Most people do not have a precise idea about the money they spend on housing and mobility and how these costs are interrelated: Less expensive real estate in the surrounding areas of larger cities seems attractive at a first glance (SCHRENK et al. 2011, 1309). However, poor accessibility of different infrastructure facilities and higher mobility costs in the long run are not considered in most cases. Hence housing decisions are often made without complete knowledge about their effects. In the end, the daily travel of long distances and the intensive use of transport come along with numerous undesirable side effects: Car dependencies, high private and public costs, congestion, and emission are just a few of them, causing increasing pressure on natural resources and a decrease in the quality of life.

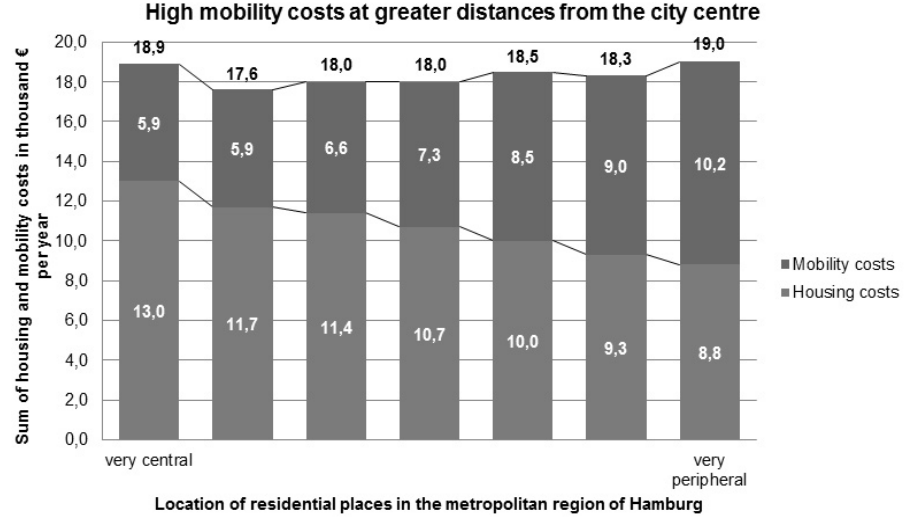

Fig. 1:

Housing and mobility costs depending on centrality (based on VCÖ 2010, 18)

1 The underlying dichotomy of urban/suburban does not exactly refer to the administrative level of urban and suburban, but relates to structurally integrated versus non-integrated locations. Thereby integrated areas encompass sites that are embedded in a settlement structure characterised by mixed land use and a compact appearance. 
This is where the Alpine space project "MORECO - Mobility and Residential Costs" comes in. MOR€CO is an international cooperation of ten project partners from five EU member states, located in the Alpine space. The starting point of the project are current economic and demographic dynamics being encountered in the Alps, which foster the growth of periurban areas, landscape fragmentation, unsuitable structures for public transport, and a dramatic rise of motorised individual traffic (BISCHOF 2013). Therefore it is the aim of $M O R E C O$ to tackle these issues by supporting sustainable and resource-friendly settlement developments: Existing infrastructure and transport axes shall be fostered, environmentally friendly mobility promoted, and urban sprawl contained. In order to achieve these goals, several tools and strategies are currently being developed, focusing on three main target groups, namely, house-hunting citizens and private households, planners and public transport organisations, as well as politicians, decision makers, and municipalities. While the article by SCHNÜRCH et al. (2014, under review) describes an approach of MOR€CO to support spatial planners and transport associations (in making elaborated decisions with respect to building land assignment, settlement structures and mobility needs), the article at hand focuses on house-hunting citizens and private households.

The goal of this work is to provide a Web-based tool for the province of Salzburg, enabling households to calculate their housing and mobility costs. It shall inform about individual

- monetary costs for rent or financing of housing and associated charges

- mobility costs, including fixed and variable expenses of vehicles as well as monthly tickets for public transport

- distances to be covered with different means of transportation

- overall expenditure of travel time

Thus, for each regular trip entered, expenditures in terms of monetary costs, time, and distance for both public transport, and (non-)motorised individual transport are opposed. Besides, the long-term effects of housing and mobility decisions, i.e. the respective longterm development of the costs and their relationship are illustrated. Based on this information, residential locations and mobility patterns may be tested: The user may compare the costs of different means of transport for the same residence and destinations, or different residential locations may be investigated, applying the same mobility behaviour. The underlying intention is to provide citizens with independent and qualified information on their (possible) residential location. By means thereof, the transparency of cost structures and their interdependences shall be enhanced, clarifying fuzzy cost perceptions. This way, the decision process on housing shall be influenced in a way that it becomes more rational and conscious. In the end, the tool shall motivate households to think about alternatives to peripheral housing locations.

\section{Tool Contextualisation in Regard to Planning Processes}

A major difficulty when tackling the problems described in the introduction, is to communicate the advantages for private households that come along with a decline of land use and traffic. EIZENHÖFER \& SINNING $(2009,141)$ perceptively state that the challenge to overcome this difficulty is to make the topic aware at the right point of time, to the right actors, with appropriate means. Needless to say that information which aims at the strengthening of integrated settlement structures and space-saving locations is not free of 
value. Rather, it is based on normative principles and on the idea of a sustainable regional development (HOLZ-RAU ET AL. 2010, 92). Thus, in order to successfully communicate the advantages of such reductions, it is important to point out relevant arguments and specific benefits for individuals. Costs seem well suited for this purpose: Their quantification facilitates the illustration of individual advantages (e.g. time or money savings), while at the same time ensuring an emotional appeal.

There are a number of spatial-related decisions that precede the citizens' everyday decisions on their destinations, routes, and transportation modes. In particular, this includes the decision on housing, but also decisions on the location and accessibility of certain destinations (e.g. workplace, educational institutions, shopping or residential locations of friends and relatives). While the former decision is more or less subject to the individual arbitration, the latter can hardly be influenced. These spatially significant decisions fall within the jurisdiction of urban, regional, and spatial planners. The distribution of land uses in space and respective developments are subject to their planning considerations. Thereby not only law-based instruments exist, but also various kinds of Web-based information material and tools that may be used to control spatial development in terms of an overarching concept. A schematic overview on some of the tools/resources that currently exist is provided by Figure 2 .

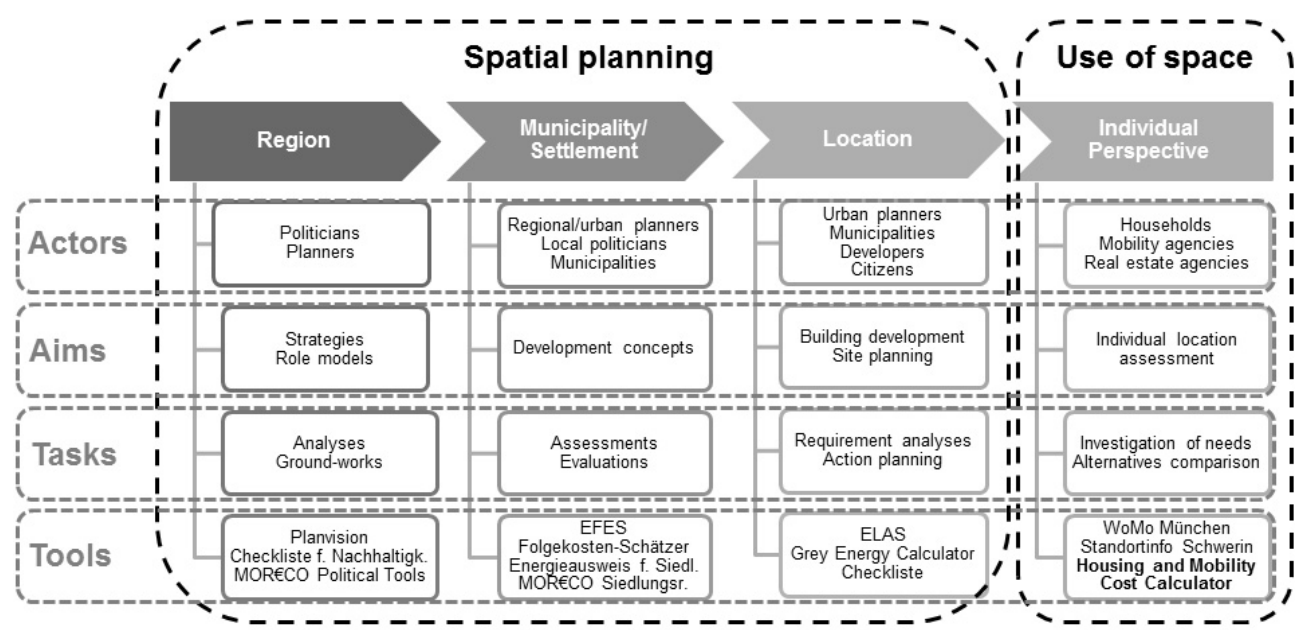

Fig. 2: Positioning of the Cost Calculator in the planning process

On a coarse regional level, where politicians (i.e. decision-makers) and planners are in charge of designing general strategies and role models for subordinate planning levels, information materials and check-lists are available for analyses and ground-works (Figure 2). These encompass instruments such as Planvision and the Checkliste für Nachhaltigkeit of the province of Salzburg. On the municipality/settlement level, regional and urban planners, as well as municipalities and local politicians are concerned with the design of regional/local development plans and concepts. Thereby these actors need to assess and evaluate different planning proposals for municipalities or settlements (Figure 2). In this context, appliances such as the tool Energieeffiziente Siedlungen (EFES), 
the Energieausweis für Siedlungen, and the MOR€CO Siedlungsrechner give assistance. Finally, on the level of individual locations/objects, not only local planning and municipalities, but also developers and even citizens are able to perform requirement analyses and action planning. This is done in the context of building development and site planning (Figure 2). These tasks are supported by instruments such as the calculator for Energetic Long-term Analysis of Settlement Structures (ELAS) or the Checkliste-Wohnbau of the city of Salzburg. It must thus be recognised that different instruments exist, each of them taking effect at specific points of time in the planning process, focusing on particular tasks and actors. The arising problem is that the development of compact structures with well-integrated locations cannot assure their efficient use: Even in well-organised traffic structures people may act in a traffic-intensive way (BAUER et al. 2006, 67).

In consequence, a regional strategy which is supposed to impact on traffic-related decisions of actors has to be based on two pillars: On the one hand, the strategy must influence decisions regarding spatial development, fostering traffic-efficient structures. On the other hand, it has to advertise and encourage the respective traffic-efficient use of these structures in everyday-mobility. That is, effective spatial structures can only have an influence if their potential is reflected in the behaviour of the citizens. Conversely, attractive destinations (e.g. workplaces, shopping locations, and leisure opportunities) need to be within close reach and accordingly accessible by public transport to allow residents to move efficiently, i.e. with reduced car traffic. BAUER et al. $(2006,67)$ correctly point out that information provision and consulting services play a pivotal role in this context, facilitating a linkage between structurally oriented spatial strategies and transport-relevant decisions of actors.

This is where applications such as the MOR€CO Housing and Mobility Cost Calculator come into play. Thus, in contrast to the tools described, these concepts take the actual use of spatial structures as a starting point, being based on the individual perspectives of households on particular locations. Allowing for the investigation of individual needs and facilitating comparisons between different options, personal assessments can be made. As it is outlined in Figure 2, these tools particularly address households looking for residential locations. However, also mobility and estate agencies may profit by offering better services.

\section{Tool Conceptualisation}

In order to develop the overall concept and functional structure of the tool, a review of current calculators in use was undertaken in the first place: Based on innovative features, prominence, and user-friendliness, a selection of six calculators was chosen for a further examination of their applicability. Amongst others, these tools encompassed the Wohn- und Mobilitätskostenrechner Hamburg (WoMo Hamburg), the Wohn- und Mobilitätsrechner des Münchner Verkehrs- und Tarifverbundes (WoMo München), the Mobilitätsausweis für Immobilien $(M A++I)$, and the Mobilitätskostenberechnung Schwerin.

The invested criteria of the strength-weakness-analysis comprised aspects on user input, output, and implementation. These were illustrated in a summary matrix. In terms of user input, the criteria encompassed the consideration of different travel purposes for the calculation of mobility costs (e.g. work, leisure, shopping, etc.), individual adoption possibilities by the user (such as financing, costs, calculations), the spatial accurateness for the calculation of mobility costs (municipality level vs. address-based), and the overall 
amount of necessary input by the user. Further, regarding the output, calculated costs (e.g. monetary, travel time, emissions, etc.), the possibility of alternative comparisons and scenario simulations, as well as graphical illustrations of the result were looked into. Last, implementation aspects encompassed the overall usability, spatial restriction of the calculator's coverage (cities, regions, and countries), the incorporation of a map/routing function, the possibility to immediately see the effect/result of a certain input change, special features, and an estimation of the required technical and maintenance effort.

From the investigation it stood out that different priorities exist for the investigated tools, each with certain strengths and particular constraints. On the one hand, there are calculators that account for both housing and mobility costs, indicating the dependencies of both cost components. On the other hand, several applications focus exclusively on mobility costs, illustrating the effect of different mobility behaviour. Furthermore, there are substantial differences regarding the amount of detail that is taken into account in terms of housing and mobility costs: Calculators that are spatially restricted to a certain area often incorporate very detailed information on costs. However, these calculators can only be used by a limited number of people. Other tools, being designed for larger areas, are based on more general assumptions which in some cases are quite vague or lack transparency.

Based on the elaboration of both proven technical possibilities and aspects that are to be avoided, the methodological, technical, and graphical demands on the MORECO Calculator were defined and later on integrated in the tool conceptualisation. Most important demands and features that were to be incorporated encompassed the following:

- Usability and adaptability: The calculator should be operated in an easy and straightforward way. Quick access to the final information should be a major goal. This should be pursued by a small amount of user input, the distinction between mandatory and optional input, and pre-filled input fields which may be modified by the user.

- Different trip purposes: It would be too short-sighted to only think of trips to work or education; private trips play an increasingly important role with regard to traffic generation. In consequence, the calculator should facilitate the investigation of various trip purposes, including work, leisure, and shopping.

- Immediate representation of changed input: It has been common practice so far to first let users provide all input and to present the result at the end. This makes it difficult for users to assess where respective costs come from and how much certain criteria impact. Therefore the calculator should directly illustrate respective changes.

- Comparison of alternatives: Similarly to some of the tools explored, the calculator should facilitate a direct comparison of two variants. These should comprise both the investigation of two different locations (assuming the same mobility behaviour) and the testing of the same location (based on changed mobility behaviour).

- Easy maintenance: It is important for the acceptance of a service that the provided information is correct and current. In order to keep the calculator up-to-date, interfaces to external services should be used rather than saving all required data locally.

As it was outlined earlier, the Cost Calculator should estimate individual expenses of a household, including monetary housing costs (consisting of rent, loan financing, and associated charges), monetary mobility costs (comprising fixed and variable car expenses as well as monthly public transport ticket costs), and travel expenditures (distances covered with different means of transportation and overall travel time). In addition, the annual 
mileage covered by car(s) and the total travel time for trips should be listed. The concept that was followed to calculate these expenses is illustrated in Figure 3.

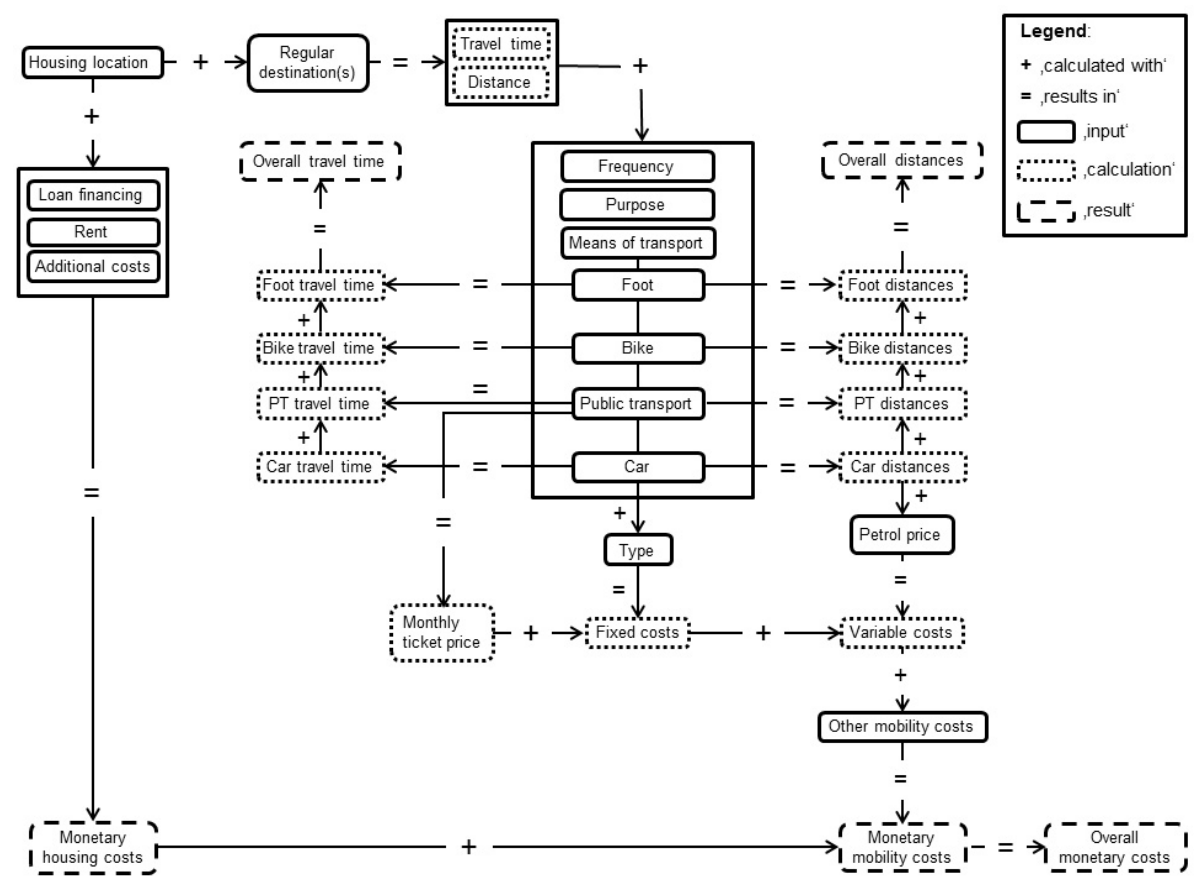

Fig. 3: Functional concept of the Housing and Mobility Cost Calculator

Beginning with the selection of a housing location, the user defines the starting point for all regular travel activities. Further, by determining the monthly rent for this location or - in the event of property purchase - the monthly financing costs and additional charges that exist, the total housing costs per month can be calculated. Monthly mobility expenses in turn are derived from regular trips which are undertaken by the user: Based on the housing location and the respective trip destination(s), travel time(s), and distance(s) for the prevailing connection(s) can be determined, initially for four travel modes (foot, bike, public transport, and car). In combination with further details on the respective trips(s), including trip frequency, purpose, and the means of transportation that is generally used, the actual travel time(s) as well as distance(s) can be calculated and stored. This is done separately for every means of transportation. Hence, by summing up travel time(s) and distance(s) for every mode, the overall time and distance expenditures for a location can be computed. Thereby it is distinguished between different trip purposes: Work/education trips are listed separately from other travels. Next, with respect to monetary mobility expenses, public transport tickets, car costs, and additional mobility charges are taken into account. The former are derived from the Salzburger Verkehrsverbund for the respective trip, based on a monthly season ticket. Monetary costs for private car use in turn are composed of fixed costs (depreciation, insurance, maintenance) and variable running costs (depending on distances and the petrol price). Besides, additional mobility costs may be included (e.g. bike 
maintenance costs). By adding up monetary housing and mobility costs, the overall monetary expenses are derived.

\section{Tool Implementation}

Subsequent to the conceptualisation of the tool, the implementation was done, based on a client-server model. Client-side, this encompassed the design of the user interface using $H T M L$ and CSS as well as the development of the interactive behaviour of the tool interface by means of JavaScript (including the JavaScript libraries jQuery, jQuery UI, and Highcharts JS). Server-side, the implementation comprised the set-up of the SQLite database (holding the data of different car categories) and the creation of two Common Gateway Interface (CGI) scripts in Python (one being responsible for the calculation of the costs, the other one to access the SQLite database). An overview on the techniques and the tool architecture is displayed in Figure 4.
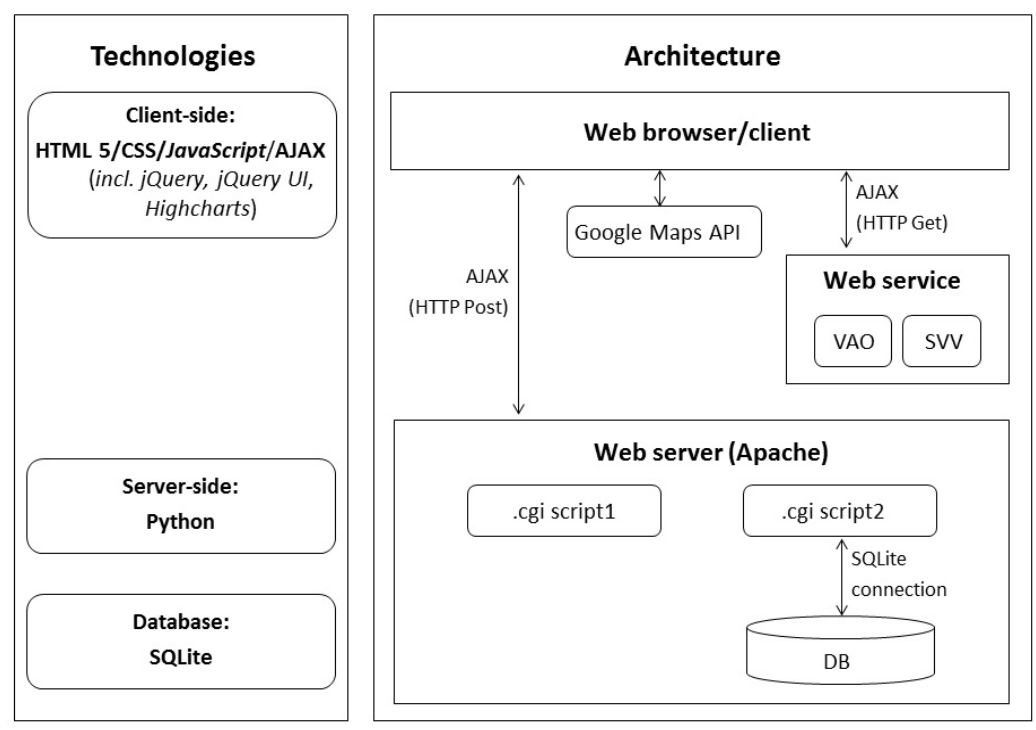

Fig. 42: Architecture of the Cost Calculator

In order to retrieve routing information (travel time and distances) as well as public transport costs, APIs were incorporated from Google Maps, the Traffic Information Austria (VAO), and the Traffic Association of Salzburg (SVV). Particular Google services encompassed the Geocoding API (to transform addresses into geographic coordinates and vice versa), the Places Autocomplete API (to provide suggestions on complete addresses, based on address strings entered by the user), as well as the Directions API (allowing for the calculation of routes between locations for travels by car, bike and on foot). Services from the $V A O$ were included to facilitate public transport routing. The $V A O$ is an Austrian wide system providing comprehensive information on traffic. It facilitates consistent crossborder routing within Austria for various transport modes, including passenger car traffic, 
public transit, bike, foot, as well as inter-modal combinations. The reason for using both the Google Directions API and VAO is that the Google API offers comprehensive routing information for car-driving, cycling and walking, while it lacks of complete information for public transport (especially bus connections). The $V A O$ API on the other hand is not yet consistent for car, bike and foot travels, but provides reliable and detailed information on public transit. In addition, the $S V V$ API was employed to include information on ticket prices for public transport: Based on a chosen route, a monthly ticket for adults is queried.

Both the $V A O$ and the $S V V$ API were not directly accessed from the JavaScript file, but included by means of a Web service, which was developed by the Traffic Consultants GmbH (TraffiCon). This separation between the JavaScript file and the services was necessary in order to avoid problems regarding the cross-domain/same origin policy, an important security concept for client-side programming.

\section{$5 \quad$ Result}

As a result of this work, the MORECO Housing and Mobility Cost Calculator for the Province of Salzburg is available online and free of charge at http://www.moreco.at/ haushaltsrechner. The layout structure of the application consists of five tabs, which are passed through one after the other. Some of the tabs comprise sub-sections, separated through accordions, which may be hinged to inspect pre-defined settings or specify particular details. Question marks next to several input fields offer hints on the expected input. A bar chart on the right hand side of the user interface illustrates housing and mobility costs, given the current input values and selections. It adapts dynamically to any input changes which refer to monetary costs. Buttons as well as underlined words open dialogue windows, where further details can be designated. Furthermore, red asterisks indicate mandatory input fields for the calculation.

\section{Conclusion and Outlook}

This work describes the conceptualisation and implementation of the MORECO Housing and Mobility Cost Calculator. It allows its user to compare alternative housing locations and distinct mobility behaviours. For the conceptualisation of the Web-based tool, state of the art communication strategies were investigated, important requirements elaborated, and innovative technological approaches explored. In addition, the application was contextualised with respect to the administrative spatial planning process, defining its temporal integration and its delineation from other existing tools and applications. On this basis it may be inferred that the potential influence of the instrument in regard to spatial determinations is considerable: Aiming at those decisions of households, which directly impact on the generation of traffic, the mobility behaviour of people may be influenced in a sense that trips become shorter and the share of eco-mobility is increased. Yet, at the end, it depends on the user of the tool, to decide which conclusions are drawn from the provided information. It is neither the purpose of the application to give instructions, nor does it pursue specific political intentions in terms of public cost savings, the disparaging of rural areas or the prevention of suburbanisation processes. 
An evaluation of the tool with respect to its usability and efficiency is currently being conducted in the scope of a seminar on sustainable mobility and regional development at the University of Salzburg. Apart from possible usability improvements, potential future enhancements of the tool may encompass the provision of information on infrastructural facilities, which are located in the close vicinity of an address (e.g. local supply, social institutions, and other services). Besides, the calculation of travel time for motorised individual traffic may be based on different times and traffic loads in an area: Depending on the time of the day and the prevailing route that is chosen, different travel time expenditures may be calculated, accounting for higher volumes of traffic at particular times of a day. Last, it is planned to spatially extend the area of application for the mobility cost calculator towards the Bavarian region. In doing so, a merging with other existing cost calculators may be facilitated in future.

\section{References}

AdAm, B., Driessen, K. \& Münter, A. (2008), Wie Städte dem Umland Paroli bieten können. Forschungsergebnisse zu Wanderungsmotiven, Standortentscheidungen und Mobilitätsverhalten. Raumforschung und Raumordnung, 66, 398-414.

Bauer, U., Glaser, J., Gutsche, J.-M., Holz-Rau, C., Koch, R., Menze, A., Rau, P. \& SteIn, A. (2006), Spezifische Entscheidungsprozesse bei den Akteuren. In: GuTSCHE, J.-M. \& KuTTER, E. (Eds.), Mobilität in Stadtregionen. Akteursorientierte Planungsstrategien für verkehrseffiziente Ballungsräume. Berlin, 63-88.

BISCHOF, D. (2013), MORECO - Mobility and residential costs. http://www.morecoproject.eu/ (30.01.2014).

EIZENHÖFER, R. \& SINNING, H. (2009), Kostenwahrheit bei der Wohnstandortwahl Entscheidungshilfe als Steuerungsinstrument für nachhaltige Siedlungsentwicklung. In: BocK, S., HinZEN, A. \& LiBBE, J. (Eds.), Nachhaltiges Flächenmanagement in der Praxis erfolgreich kommunizieren. Ansätze und Beispiele aus dem Förderschwerpunkt REFINA. Berlin, 133-144.

Holz-Rau, C., Schwarze, B. \& Scheiner, J. (2010), Wohnstandortinformationen für private Haushalte. Grundlagen und Erfahrungen aus zwei Modellstädten. Dortmunder Beiträge zur Raumplanung, 9. Dortmund.

SchnÜrCh, D., Haslauer, E., CAStellazzi, B. \& Prinz, T. (2014), MOR€CO Siedlungsrechner - Planungstool zur Abschätzung mobilitätsbezogener Folgekosten im Wohnbau. In: Strobl, J., Blaschke, T., Griesebner, G. \& Zagel, B. (Eds.), Angewandte Geoinformatik 2014. Beiträge zum 26. AGIT-Symposium Salzburg. Berlin/Offenbach.

Schrenk, M., EIzInger, C., EGGER, T., DörrZAPF, L. \& FrAnZ, S. (2011), Mobilität prägt Städte und Regionen - MAI, der „Mobilitätsausweis für Immobilien” als Promotor nachhaltiger Mobilität. In: SCHRENK, M. (Ed.), Proceedings REAL CORP 2011. Tagungsband. Essen, 1309-1314.

VERKEHRSCLUB ÖSTERREICH (VCÖ) (2007), Einfluss der Raumordnung auf die Verkehrsentwicklung. Mobilität mit Zukunft. Vienna.

VERKEHRSCLUB ÖSTERREICH (VCÖ) (2010), Wie Wohnen Mobilität lenkt. Mobilität mit Zukunft. Vienna.

WÜrdemann, G. \& Held, M. (2009), Das hochwertige Gut Mobilität und die kostbare Ressource Öl. Informationen zur Raumentwicklung, 12, 751-764. 